\title{
Challenges in Biotechnology at LLNL: From Genes to Proteins
}

\author{
J. S. Albala
}

March 11, 1999

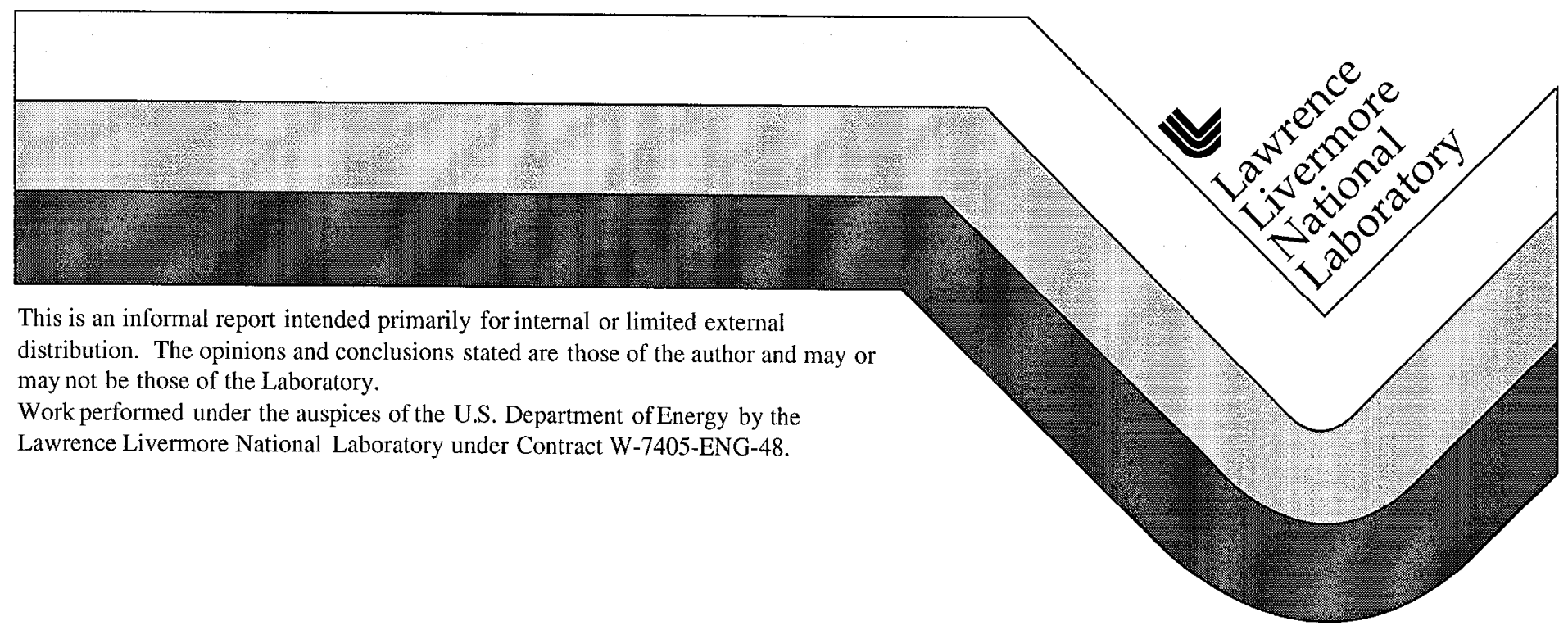




\section{DISCLAIMER}

This document was prepared as an acccount of work sponsored by an agency of the United States Government. Neither the United States Government nor the University of California nor any of their employees, makes any warranty, express or implied, or assumes any legal liability or responsibility for the accuracy, completeness, or usefulness of any information, apparatus, product, or process disclosed, or represents that its use would not infringe privately own rights. Reference herein to any specific commercial products, process, or service by trade name, trademark, manufacturer, or otherwise, does not necessarily constitute or imply its endorsement, recommendation, or favoring by the United States Government or the University of California. The views and opinions of authors expressed herein do not necessarily state or reflect those of the United States Government or the University of California, and shall not be used for advertising or product endorsement purposes.

This report has been reproduced directly from the best available copy.

A vailable to DOE and DOE contractors from the Office of Scientific and Techrical Information P.O. Box 62, Oak Ridge. TN 37831

Prices available from (615) 576-8401, FTS 626-8401

Available to the public from the National Techrical Information Service

U.S. Department of Commerce 5285 Port Royal Rd., Springfield, VA 22161 


\title{
Challenges in Biotechnology at LLNL: From Genes to Proteins
}

\author{
Biology and Biotechnology Research Program \\ Exploratory Research in the Directorates \\ Final Report \\ Joanna S. Albala
}

This effort has undertaken the task of developing a link between the genomics, DNA repair and structural biology efforts within the Biology and Biotechnology Research Program at LLNL. Through the advent of the I. M. A. G. E. (Integrated Molecular Analysis of Genomes and their Expression) Consortium, a world-wide effort to catalog the largest public collection of genes, incepted and maintained within BBRP, it is now possible to systematically express the protein complement of these to further elucidate novel gene function and structure. The work has ensued in four phases, outlined as follows: (I). Gene and System selection; (II). Protein expression and purification; (III). Structural analysis; and (IV). Biological integration. Proteins to be expressed have been those of high programmatic interest. This include, in particular, proteins involved in the maintenance of genome integrity, particularly those involved in the repair of DNA damage, including ERCC1, ERCC4, XRCC2, XRCC3, XRCC9, HEX1, APN1, p53, RAD51B, RAD51C, and RAD51. Full-length cDNA cognates of selected genes were isolated, and cloned into baculovirus-based expression vectors. The baculoviral expression system for protein over-expression is now well-established in the Albala laboratory. Procedures have been successfully optimized for full-length cDNA cloning into expression vectors for protein expression from recombinant constructs. This includes the reagents, cell lines, techniques necessary for expression of recombinant baculoviral constructs in Spodoptera frugiperda (Sf9) cells. The laboratory has also generated a high-throughput baculoviral expression paradigm for large scale expression and purification of human recombinant proteins amenable to automation.

Unlike cDNAs, proteins are much more unique in composition and thus more difficult to study. Initally, each recombinant protein produced in the baculoviral expression system contained a six amino acid $\mathrm{N}$-terminal histidine tag for purification by metal chelate affinity chromatography. This however proved to be only an initial purification step. Subsequent analysis included applying several different experimental conditions to obtain purified protein and this proved problematic. Another fusion tag was chosen to replace the hexahistidine tag to facilitate an immunoaffinity purification scheme. A glutamate epitope tag was introduced into the baculoviral transfer vector into which the gene of interest was initially cloned. The recombinant baculovirus is generated by co-transfection of this vector and baculoviral DNA into insect cells where a recombination event places the gene of interest into the baculoviral genome driven by a strong natural viral gene promoter. Production of recombinant proteins within the insect cells now generated an N-terminal fusion protein containing a glutamate epitope tag which was 
subsequently exploited for purification of the recombinant protein. This enabled the one-step purification of several proteins which are currently being scaled for structural analysis. Expressed proteins will be purified and transfered to the structural biology group for x-ray diffraction and NMR study.

We have continued our efforts to understand the function of the novel DNA repair protein, RAD51B. RAD51B was initially identified in the I. M. A. G. E. collection. We have cloned, expressed, and purified recombinant RAD51B using baculovirus expression. RAD51B and RAD51C, another putative DNA repair protein, have been shown to interact by yeast two-hybrid analysis. Co-infection of recombinant RAD51B and RAD51C baculovirusus into Sf9 cells followed by immunoaffinity chromatography has demonstrated that these proteins form a true heterocomplex (Figure 1). Additional biochemical analysis has confirmed these results. Studies in the laboratory are aimed at understanding the role of the RAD51B-RAD51C heterocomplex in homologous recombination and DNA repair. RAD51B and RAD51C have been shown by yeast two-hybrid analysis to coexist in a larger multi-protein complex with RAD51. RAD51 co-localizes with the tumor suppressor proteins, BRCA1 and BRCA2, and has been implicated in breast carcinogenesis. The role for RAD51B within this larger complex and in these processes is currently being explored. Using real-time quantitative PCR techniques, known as Taqman ${ }^{\mathrm{TM}}$, initial studies have shown that RAD51B expression is down-regulated in a malignant breast cancer cell line. We aim to understand if there is decreased or loss of $R A D 51 B$ expression in a variety of breast cancer cell lines to determine a possible biological role for RAD51B in breast cancer.

Figure 1: Purification of a RAD51B-RAD51C complex after co-infection.

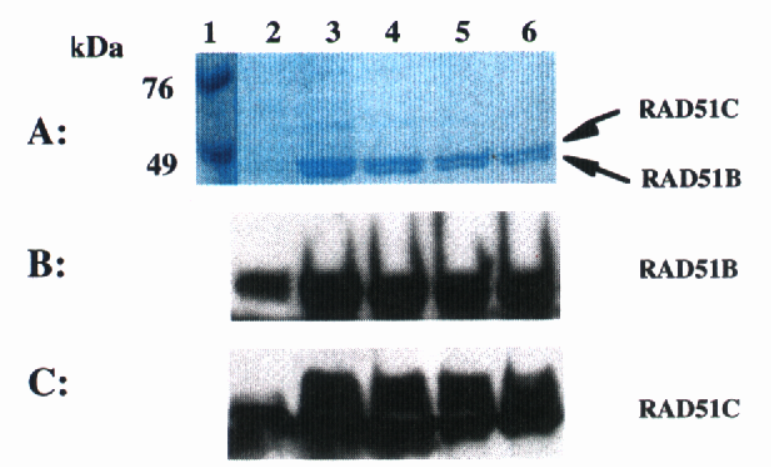

The RAD51B-EE baculovirus was co-infected into $S f 9$ insect cells with another recombinant baculovirus construct containing untagged RAD51C. The RAD51B-RAD51C protein complex was purified from the insect celly lysate by immunoaffinity chromatography. RAD51C co-purified with RAD51B$\mathrm{EE}$ and was eluted from the GluGlu column by its interaction with the RAD51B-EE protein. Pane A: Coomaissie blue-stained gel of the purification of the RAD51B-RAD51C complex. Panel B: Western blot of the purification of the RAD51B-RAD51C complex incubated with the RAD51B affinity-purified polyclonal peptide antibody. Panel C: Western blot of the purification of the RAD51B-RAD51C complex incubated with the RAD51C polyclonal antibody, C1. Lane 1: Molecular weight standards. Lanes 2-6: Peptide elution of the RAD51B-RAD51C complex. 
Using the technology of baculovirus expression, we have developed a high-throughput system to express and purify proteins from I. M. A. G. E. cDNAs clones to generate the "human proteome", the protein complement of the human genome. To date, this work has demonstrated $42 \%$ recombinant protein expression whereby 34 proteins were expressed from a single 96 well plate (Figure 2). This technology has broad application. In order to understand the biology of the genome, individual genes will need to be identified, expressed and examined for functional characteristics so that the underlying mechanisms of the cell can be revealed. This system will allow for this type of analysis as well as advancing technology for high-throughput, automatable crystallization and structural analysis of multitudes of recombinant protein.

Figure 2: Western blot of soluble proteins expressed by recombinant baculovirus-infected cells in a 96-well format.

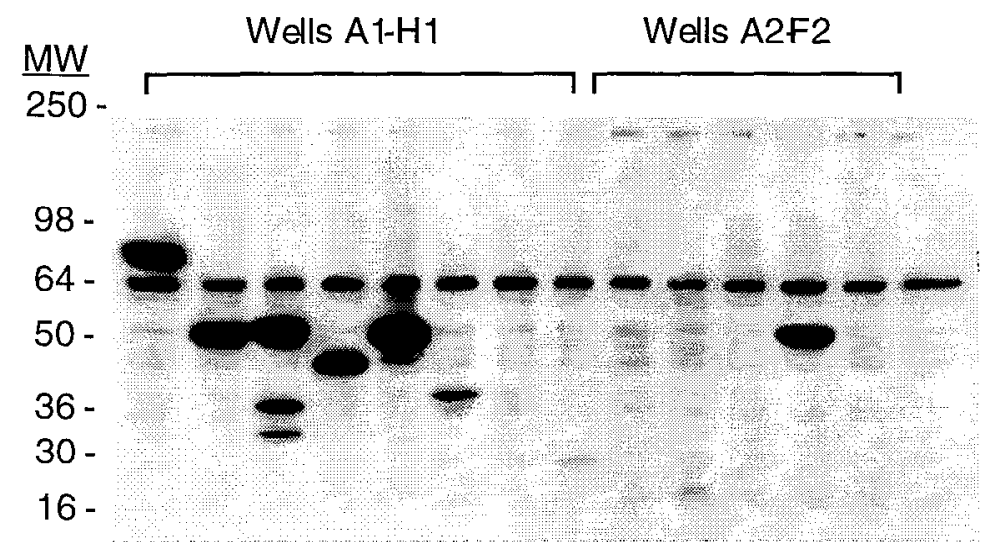

Infected cells from 24 well plates were lysed in $85 \mathrm{ul}$ lysis buffer $(10 \mathrm{mM}$ Tris $\mathrm{pH}$ 8, $100 \mathrm{mM} \mathrm{NaCl}, 1 \mathrm{mM}$ EDTA, $1 \mathrm{mM}$ DTT, $1 \%$ NP40, including a cocktail of standard protease inhibitors) and clarified by low speed centrifugation. $20 \mathrm{ul}$ of lysate was analyzed on a $4-20 \%$ SDS-PAGE gradient gel, blotted onto PVDF membranes, probed with Glu-Glu antibody and developed using enhanced chemiluminescence (ECL).These samples represent the first 14 wells from the protoplate. Overall, 34 of 81 wells yielded recombinant protein (visible band observed) yielding $42 \%$ recombinant protein expression. Note: Each well contains a non-specific band at 64 kilodaltons.

In summary, these efforts have resulted in the implementation of a eukaryotic expression system for functional and structural analysis of proteins, the identification and characterization of novel proteins involved in genomic integrity and possibly carcinogenesis, and the advent of a novel, automable, high-throughput system for the expression and purification of hundreds of proteins in parallel.

*This work was performed under the auspices of the U.S. Department of Energy by Lawrence Livermore National Laboratory under contract No. W-7405-Eng-48. 